\title{
Analytical Method for Reaction with Diffusion of Reactants in High-Viscosity Liquid under Simple Shear Flow
}

\author{
Mitsuo Kamiwano and Fumio Saito
}

\begin{abstract}
Dept. of Chem. Eng., Yokohama Nat'l. Univ., Yokohama 240
Key Words : Mixing, High-Viscosity Liquid, Mixing Time, Simple Shear Flow, Chemical Reaction, Molecular Diffusion, Analytical Method

The progressive process of reaction with diffusion of reactants in high-viscosity liquid under simple shear flow was studied. The reaction process is simulated by combining the reaction and diffusion equation with the equation representing the decrease of segregation scale. Reaction experiments were carried out by using a cylindrical vessel with coaxial cylinder. $\mathrm{I}_{2}$ and $\mathrm{Na}_{2} \mathrm{~S}_{2} \mathrm{O}_{3}$, each dissolved in corn syrup, were chosen as the reaction system. The variation of concentration of each reactant with time and the time until the end point of reaction were found to be in fairly good agreement with those simulated analytically.
\end{abstract}

\section{過熱 $\mathrm{NaCl}$ 水溶液中の気泡成長速度の簡易表示式 ${ }^{\dagger}$}

\author{
宮武修 \\ 九州大学工学部 化学機械工学科 \\ 田中逸夫* \\ 九州大学機能物質科学研究所 ${ }^{+\dagger}$
}

はじめに

フラッシュ蒸発, 沸騰などの現象を解明する基礎研究 として, 過熱液中の気泡成長に関する多くの研究がなさ れてきたが, 不揮発性溶質を含む溶液は対象とされてい なかった。そこで著者らは，まず，その溶液を対象とし た気泡成長に関与する基礎方程式群を組み立て，それら を $\mathrm{NaCl}$ 水溶液について数值解析し, 気泡壁液側で生ず る溶質の濃縮, 溶質による沸点上昇（過熱蒸気の発生） が気泡成長に及ぼす影響を明らかにしだ）次いで，独自 の実験方法を用い，溶液温度，溶液濃度および周讲圧力 を変えて, 均一過熱 $\mathrm{NaCl}$ 水溶液中の気泡成長に関する 実験結果を取得し, 数值解析結果の妥当性を検証した ${ }^{7}$.

† 1987年 6 月 30 日受理

+十 \% 812 福岡市東区箱崎 6-10-1

H† \% 814 春日市春日公園 6-1

* 岐皁大学農学部 農業工学科
本報では, それらの結果ならびに補足的に求めた数值 解析結果を援用し, 均一過熱 $\mathrm{NaCl}$ 水溶液中の気泡成長 速度を予測する簡易表示式を導出する.

\section{数值解析結果の再検討}

溶液を指定すると, 不揮発性溶質を含む過熱溶液中の 気泡成長速度は，それぞれ無限遠に拈ける溶液温度 $T_{\infty}$, 溶質の質量分率 $\omega_{\infty}$ 抢よび溶液内压力 $p_{\infty}$ によって定まる. $p_{\infty}$ の代わりに, 次式で定義した過熱度 $\Delta T_{s}$ または初期 の気泡内外圧力差 $\Delta P_{0}$ を採用してもよい.

$$
\begin{aligned}
\Delta T_{s} & =T_{\infty}-T_{e} \\
\Delta P_{0} & =(P)_{T_{\infty}}, \omega_{\infty}-p_{\infty}
\end{aligned}
$$

ここで, $T_{e}$ は次式の関係を満たす平衡温度， $P$ は溶液 の蒸気圧であり，（）外の添字は（）内の量を算定 する温度 $T$ および溶質の質量分率 $\omega$ を表す (以下の Eqs. (3), (7), (8)の同様の添字についても同様).

$$
p_{\infty}=(P)_{T_{e}, \omega_{\infty}}
$$



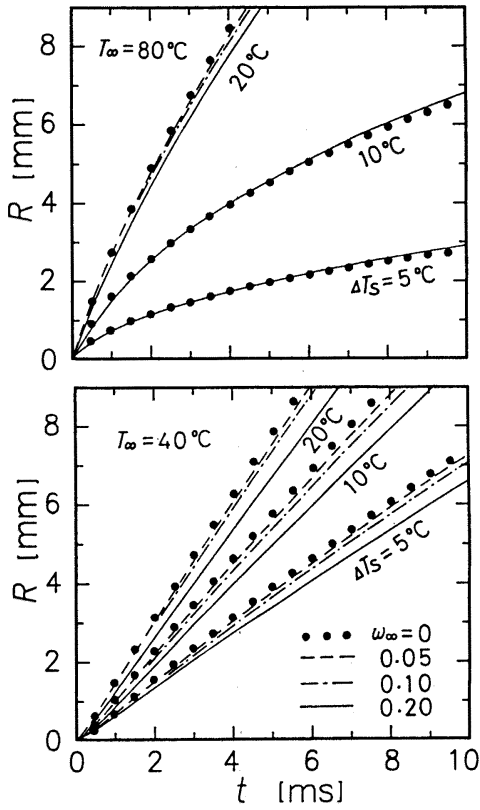

(a)
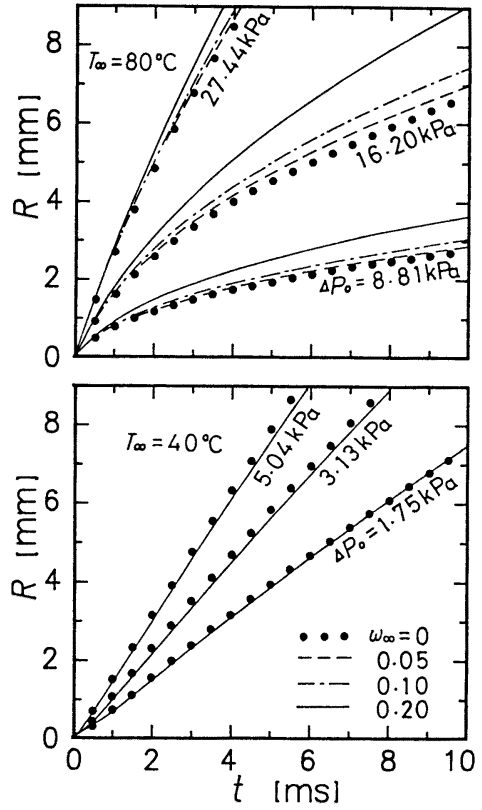

(b)

Fig. 1 Variation of bubble radius $R$ with time $t$ (a) superheat $\Delta T_{s}$ and (b) initial pressure difference between inside and outside of the bubble $\Delta P_{0}$ are taken as parameters

任意の $T_{\infty}$ のもとで，気泡成長速度に及ぼす $\omega_{\infty}$ の影響 は， $p_{\infty}$ を媒介变数にとると顕著に現れるのに対し， $\Delta T_{s}$ を媒介変数にとると慣性支配域を除いてほとんど現れな いことは，その理由ゔけを含めて前報胡で示した．

気泡壁での液温度低下が比較的緩慢で, 気泡内外圧力 差によって主に気泡が成長する慣性支配域では， $\Delta P_{0}$ を 新たに媒介变数にとれば $\omega_{\infty}$ の影響が現れないことは容 易に予測でき，乙のととを気泡半径 $R$ 之時間 $t$ の関係で 例証したのが Fig. 1である. (a), (b) それぞれの図から, 液本体から気泡壁への熱伝達によって主に気泡が成長す 万熱伝達支配域 $\left(R \propto t^{1 / 2}\right)$ では $\Delta T_{s}$ を, 慣性支配域 $(R \propto$ $t)$ では $\Delta P_{0}$ を媒介変数にとれば $\omega_{\infty}$ O)影響はほとんど現 机ず，純溶媒（水），すなわち純液に対する気泡成長の 関係が溶液に対してもそのまま適用できるてとがわかる.

\section{気泡成長速度を予測する簡易表示式の導出}

過熱純液中の気泡成長速度に関し，慣性支配と熱伝達 支配の両域で適用できるMikic らの近似式 ${ }^{3)}$ ，数值解 析結果に基づき，蒸気圧と温度の関係の非線形性，表面 張力に起因する気泡成長遅れ，気泡成長加速度打よび臨 界気泡径からの気泡成長の各影響が考慮されるように修 正するととにより，著者らは実験結果と良好に一致する 簡易表示式を導いている ${ }^{4,5}$. 純液に対するての簡易表示 式は，純液として純溶媒をとり， $p_{\infty}$ に対応する純溶媒の
飽和温度を溶液の平衡温度 $T_{e}$ で, 純溶媒の蒸気圧を溶液 の蒸気压 $P$ で惪換すれば，すなおちEqs. (1), (2) で定義 した $\Delta T_{s} ， \Delta P_{0}$ を用いれば，溶液に対する簡易表示式とな りうるととが前項の数值解析結果の再検討でわかった. そこで，乙れらの置換を施すと無次元気泡半径 $R^{*}$ 之無 次元時間 $t *$ の関係について次式が得られる.

$$
\begin{aligned}
R^{*}= & \frac{2}{3}\left[1+\frac{t^{*}}{3} \exp \left\{-\left(t^{*}+1\right)^{1 / 2}\right\}\right] \\
\text { 乙こで, } & \left\{\left(t^{*}+1\right)^{3 / 2}-\left(t^{*}\right)^{3 / 2}-1\right\} \\
R^{*} & =\left(A / B^{2}\right)\left(R-R_{c}\right) \\
t^{*} & =\left(\frac{A}{B}\right)^{2}\left[t-\frac{6 R_{c}}{A}\left[1-\exp \left\{-\left(\frac{A t}{6 R_{c}}\right)^{2}\right\}\right]\right] \\
A & =\left[(2 / 3)\left\{\Delta P_{0} /\left(\rho_{l}\right)_{T_{\infty}}\right\}\right]^{1 / 2} \\
B & =\left(\frac{12}{\pi}\right)^{1 / 2}\left\{\frac{\Delta T_{s}}{\left(\rho_{v}\right)_{T_{r}}}\right\}\left(\frac{\alpha_{l}^{1 / 2} c_{l} \rho_{l}}{h_{f g}}\right)_{T_{\theta}} \\
R_{c} & =2 \sigma / \Delta P_{0}
\end{aligned}
$$

てれらの式中の物性值はすべて純溶媒に対するあので あり, 温度依存性の大きい溶媒の飽和蒸父密度 $\rho_{v}$ は次式 で表される代表温度 $T_{r}$ に打いて算定する ${ }^{4)}$.

$$
\begin{aligned}
T_{r}= & T_{e}+\left(T_{\infty}-T_{e}\right)\left[1-2\left(t_{r}{ }^{*}\right)^{1 / 2}\left\{\left(t_{r}{ }^{*}+1\right)^{1 / 2}\right.\right. \\
& \left.\left.-\left(t_{r}{ }^{*}\right)^{1 / 2}\right\}\right]
\end{aligned}
$$



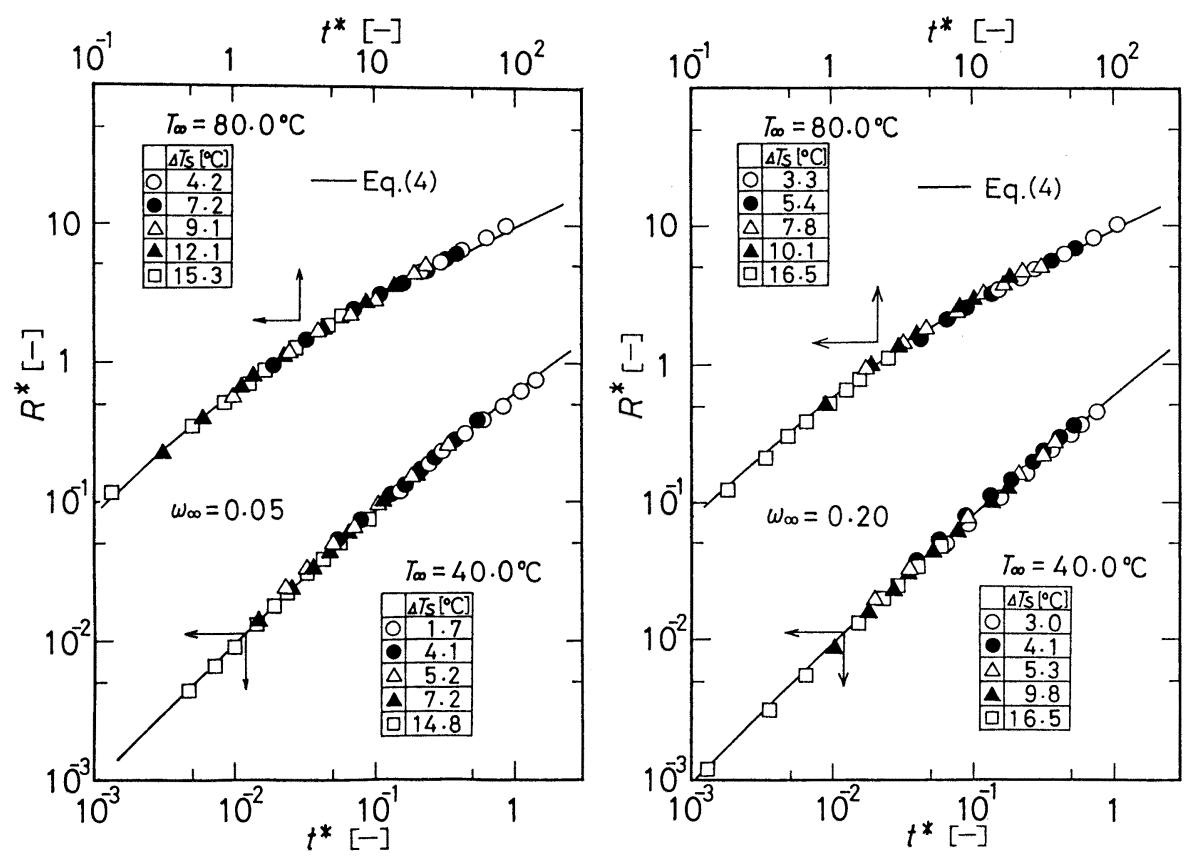

Fig. 3 Comparison of simplified expression Eq. (4) with experimental results ${ }^{7)}$

ここで,

$$
t_{r}^{*}=(1 / 2)(A / B)^{2}\left\{t_{u}-\left(6 R_{c} / A\right)\right\}
$$

であり, $t_{u}$ は当該時間範囲の上限（本報では, Fig. 2 亿 図示した範囲の上限 $t_{u}=10^{-2} \mathrm{~s}$ とした) である.

簡易表示式Eq. (4) 亡 $\mathrm{NaCl}$ 水溶液に対する数值解析結 果 $^{6}$ 打よび実験結果 ${ }^{7}$ の比較を，それぞれFigs. 2,3亿示 した。いずれも極めて良好に一致しており，溶液に対す る簡易表示式Eq.(4)の妥当性が検証されたとみなせる.

なお，導いた簡易表示式 Eq. (4)には， $\Delta P_{0}$ 之 $\Delta T_{s}$ に溶 液の特性が含まれているが, 結果的に物質拡散係数は含 まれなかった，その理由は，物質拡散係数を考慮するこ とによって定まる気泡壁液側での溶質の濃縮は沸点上昇 をより大きくさせ，i）気泡内蒸気圧の低下と，ii）発生 蒸気の過熱の増大（発生蒸気密度の低下）をむたらすか らである。すなわち，i），ii）はそれぞれ，気泡成長を減 少，増大させる影響を及ぼし ，双方の影響がほとんど相 殺された結果によるものである.

この双方の影響の相殺効果は, 程度の差はあるにせよ, 一般的に現れるものであり, 溶液濃度が極端に高くなら ない限り, 他の電解質水溶液に対しても Eq. (4)が以下の 理由で成立するものと考元られる。すなわち，代表的な 34 種類の電解質水溶液之 $\mathrm{NaCl}$ 水溶液の物質拡散係数の 比は，無限希釈に扔いて $0.5\left(\mathrm{CuSO}_{4}, \mathrm{ZnSO}_{4}\right) \sim 2.1$ $(\mathrm{HCl}, \mathrm{HBr}) \sigma$ 範囲にある ${ }^{1,2}$. 物質拡散係数が小さいほ
ど，気泡壁液側で溶質はより濃縮されるので，気泡成長 に及ぼす物質拡散係数の影響は顕著になる. $\mathrm{NaCl}$ 水溶 液について物質拡散係数を仮に上記の比の範国をかなり 下まわる $1 / 3$ の值によっても, 気泡壁液側での溶質の濃 度上算割合が最屯高くなる $T_{\infty}=80^{\circ} \mathrm{C}, \omega_{\infty}=0.20, \Delta T_{s}=$ $20^{\circ} \mathrm{C}$ ( ) 場合 ${ }^{6}$ 亿打いて，Rの数値解析值は $4 \%$ 以内の低 下にとどまり，依然として気泡成長に及ぼす双方の影響 はほとんど相殺される.

\section{おわりに}

慣性支配域から熱伝達支配域にわたって, 均一過熱 $\mathrm{NaCl}$ 水溶液中の気泡成長速度を予測できる簡易表示式 を導いた。乙の簡男表示式は, 溶液濃度か極端に高くな らない限り，少なくとも電解質水溶液に対して一般性を 失うことなく適用できるとみなせよう.

\section{Nomenclature}

$$
\begin{aligned}
& A=\text { defined by Eq. }(7) \\
& B=\text { defined by Eq. }(8) \\
& c_{l}=\text { specific heat of pure solvent } \\
& h_{f g}=\text { latent heat of vaporization } \\
& P=\text { vapor pressure of solution } \\
& p_{\infty}=\text { pressure in solution far from the bubble } \\
& R=\text { bubble radius } \\
& R_{c}=\text { critical bubble radius }
\end{aligned}
$$$$
[\mathrm{m} / \mathrm{s}]
$$$$
\left[\mathrm{m} / \mathrm{s}^{1 / 2}\right]
$$$$
[\mathrm{J} /(\mathrm{kg} \cdot \mathrm{K})]
$$$$
[\mathrm{J} / \mathrm{kg}]
$$ 
$R^{*}=$ dimensionless bubble radius defined by Eq. (5)

$T_{e}=$ equilibrium temperature of solution corresponding to $p_{\infty}$

$T_{r}=$ reference temperature at which $\rho_{v}$ is evaluated

$T_{\infty}=$ temperature of solution far from the bubble

$t=$ time

$t_{v}=$ upper limit of time during the period concerned

$t^{*}=$ dimensionless time defined by Eq. (6)

$t_{r}{ }^{*}=$ dimensionless time for estimating $T_{r}$

$\alpha_{l}=$ thermal diffusivity of pure solvent

$\Delta P_{0}=$ initial pressure difference between inside and outside of the bubble

$\Delta T_{s}=$ superheat defined by Eq. (1)

$$
\rho_{l}=\text { density of pure solvent }
$$

$\rho_{v}=$ density of pure solvent vapor

$\sigma=$ surface tension

$\omega_{\infty}=$ mass fraction of solute in solution far from the bubble

\section{Literature cited}

1) Denki Kagaku Kyokai (ed.) : “Denki Kagaku Benran”, p. 64, Maruzen Co., Tokyo (1985)

2) Kagaku Kogaku Kyokai (ed.) : “Kagaku Kogaku Benran”, p. 69, Maruzen Co., Tokyo (1978)

3) Mikic, B.B., W.M.Rohsenow and P.Griffith: Int. J. Heat Mass Transfer, 13, 657 (1970)

4) Miyatake, O. and I. Tanaka: Trans. JSME, Ser. B, 48, 355 (1982)

5) idem: ibid., 48, 364 (1982)

6) idem: Kagaku Kogaku Ronbunshu, 13, 678 (1987)

7) Miyatake, O., I. Tanaka and Y.Tsutsui : ibid., 13, 685 (1987)

\title{
Simplified Expression for Rate of Bubble Growth in Superheated Aqueous $\mathrm{NaCl}$ Solutions
}

\author{
Osamu Miyatake \\ Dept. of Chem. Eng., Kyushu Univ., Fukuoka 812
}

Itsuo Tanaka*

Inst. of Advanced Material Study, Kyushu Univ., Kasuga 814

Key Words: Evaporation, Bubble Growth Rate, Superheated Liquid, Sodium Chloride Solution, Simplified Expression, Flash Evaporation

A simplified dimensionless expression suitable for predicting the growth rate of a vapor bubble in uniformly superheated aqueous solutions of sodium chloride was derived from the results of numerical analysis. The expression is generally valid in both inertia-controlled and heat transfer-controlled growth regions. The derived expression is also found to be in fair agreement with previous experimental results.

* Dept. of Agric. Eng., Gifu Univ. 